\title{
DETECTION OF ROOT CANAL ANATOMICAL VARIATIONS IN MANDIBULAR PREMOLARS IN AN EGYPTIAN POPULATION
}

\author{
Ahmed M. Nashat ${ }^{1 * B D S}$, Mohamed M. Ibrahim² ${ }^{2 h D}$, Rania M. El Backly ${ }^{3 \text { PhD }}$.
}

\begin{abstract}
INTRODUCTION: Mandibular premolars are some of the most challenging teeth to be treated endodontically, with wide variations in canal anatomy, unexpected morphology, and high incidence of rare configurations.

OBJECTIVES: Investigation of root canal anatomical configurations in mandibular premolars in an Egyptian population, and evaluation of Digital Periapical Radiography efficacy in root canal anatomy identification.

MATERIALS AND METHODS: The study was approved by the ethical committee at faculty of dentistry, Alexandria University (IRBNO:00010556-IORG0008839). One hundred and eighteen extracted(for periodontal reasons) human mandibular premolars were randomly selected from an Egyptian population at the outpatient clinic of the maxillofacial department in Alexandria University according to selection criteria that ensures the presence of a fully formed root canal system that was neither filled or deteriorated by decay, or restorations, or resorption or cracks. No information regarding age or gender were collected. All samples were mounted in acrylic blocks and scanned by digital periapical radiography from two horizontal angles and then dissected by grinding longitudinally buccolingually till visualizing root canal anatomy highlighted by methylene blue dye. Digital radiographs were analyzed by 5 evaluators who identified the anatomy of each sample according to Vertucci's classification. Then anatomy displayed by each dissected sample was recorded. Data were statistically analyzed.

RESULTS: (Type-I) was the most prevalent configuration (76.3\%), followed by Type-V (16.9\%) and Type-III (5.1\%), and only (1.7\%) presented 3-Canal configuration. Periapical radiography failed to correctly detect root canal anatomy in 24 teeth (20.3\%).

CONCLUSIONS: Presence of more than one canal in mandibular premolars is not rare in the Egyptian population, and periapical radiography is not reliable to identify root canal anatomy of mandibular premolars.

KEYWORDS: Mandibular premolars, Vertucci’s classification, Root canal anatomy, Periapical radiography, Sectioning

RUNING TITLE: Root canal anatomical variations in mandibular premolars.
\end{abstract}

1 Instructor at Conservative Dentistry Department, Faculty of Dentistry, Pharos University in Alexandria, Egypt.

2 Professor Emeritus of Endodontics, Conservative Dentistry Department, Faculty of Dentistry, Alexandria University, Egypt.

3 Associate Professor of Endodontics, Conservative Dentistry Department, Faculty of Dentistry, Alexandria University, Egypt

*Corresponding author:

E-mail: Ahmed.Nashat@Pua.edu.eg

\section{INTRODUCTION}

Presence of missed un-treated canals is a major cause of root canal treatment failure, with reported high prevalence of apical lesions in teeth with missed canals (1). Missing a canal during root canal treatment procedures is usually caused by insufficient knowledge of root canal morphology or complicated root canal configuration.

Root canal treatment success depends mainly on knowledge of the root canal system morphology, successful negotiation, cleaning, shaping, and obturation. Knowledge of root canal anatomy is a cornerstone where subsequent procedures build up (21, 22).

Various forms and configurations of root canal system are displayed in human permanent dentition (23,24,25). Documentation of anatomic configurations of root canals has been made in different populations using different techniques such as Teeth Clearing, Teeth Sectioning and Radiography. Root canal anatomical variations is influenced by different factors including gender and ethnicity with an observed greater impact of the latter $(3,4,5,6)$.
Mandibular premolars are teeth that present difficulties during root canal treatment procedures due to wide anatomical variations and complicated branching presented. Although the single canal system is the most commonly reported anatomy in mandibular premolars, presence of more than one canal is not rarely reported in different ethnic groups $(3,4,5,6)$.

Periapical radiography is still the most implemented imaging method for root canals investigation in clinical practice due to the complementary information it provides with minimum cost, radiation exposure and time. Introduction of digital periapical radiography systems decreased radiation exposure to a great extent. In addition to that, introduction of viewing softwares improved convenience drastically with easier viewing and abilities to adjust contrast, brightness, color and magnification. Despite of its widespread adoption, periapical radiography limitations affects accurate assessment of root canal morphology. Periapical radiography produces twodimensional images of three-dimensional complex objects in presence of other superimposing structures which in result hinders accurate assessment. In addition to that, occurrence of geometric distortion of the radiographic image is 
inevitable due to the complex anatomy of the maxillo-facial skeleton $(4,17$, and 18$)$.

To our knowledge, there are no studies that have been conducted on Egyptians to assess the prevalence of different root canal anatomies in mandibular premolars using two different methods. Therefore, this study aimed to address the prevalence of different root canal configurations in mandibular premolars in an Egyptian population, and the efficacy of periapical radiography to assess root canal morphology of mandibular premolars.

The hypothesis of the current study is that, there is no significant difference between Egyptians and other ethnic groups in prevalence of different root canal configurations in mandibular premolars, and there is no difference between Digital Periapical Radiography and tooth sectioning in identification abilities.

\section{MATERIALS AND METHODS}

The study was approved by the ethical committee at faculty of dentistry, Alexandria University (IRBNO: 00010556IORG0008839). A total of one hundred and eighteen extracted (for periodontal reasons) human mandibular premolars were randomly selected for this study from an Egyptian population at the outpatient clinic of the maxillofacial department in Alexandria University according to selection criteria that ensures the presence o $\mathrm{f}$ a fully formed root canal system that was neither filled or deteriorated by decay, or restorations, or resorption or cracks. No information regarding age or gender were collected. Teeth were placed in sodium hypochlorite for one hour to remove any organic material, then hand scalers were used afterwards to remove any tissue remnants or calculus. Afterwards, teeth were rinsed by tap water and stored in saline. Finally, all specimens were placed in standardized cylindrical acrylic blocks using copper mold. (Figure-1)

Specimens were scanned from two standardized horizontal angles using digital preapical sensor SOPIX-2 (Acteon, Merignac, France), and dental X-ray device TIMEX-70E (Gnatus, Sao Paulo, Brazil). (Figure-2)

(a)
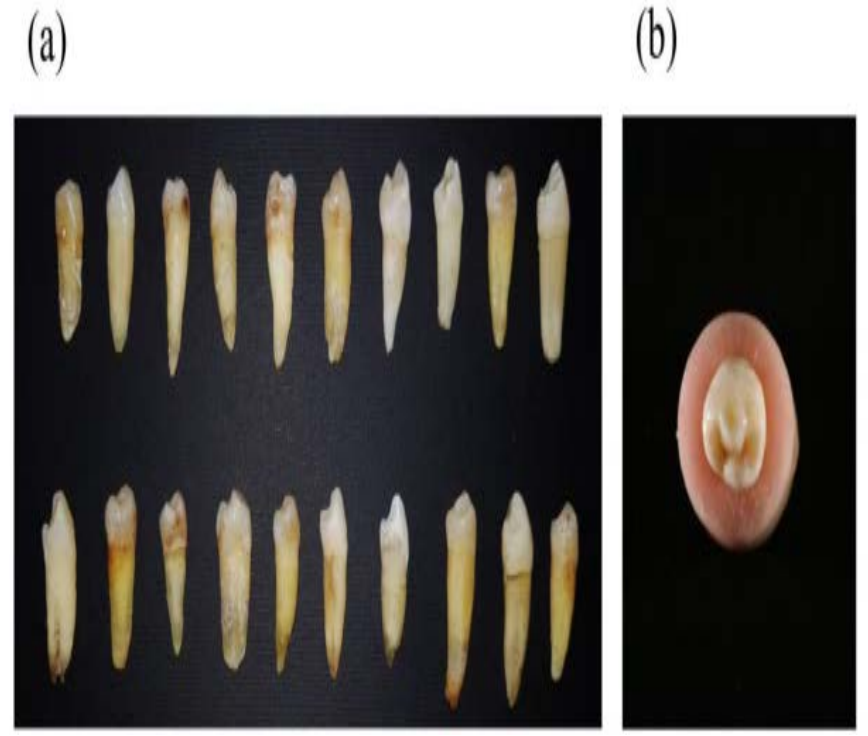

Figure (1): (a) Representative samples of the selected 118 teeth, (b) Teeth mounting in cylindrical acrylic blocks. (a)
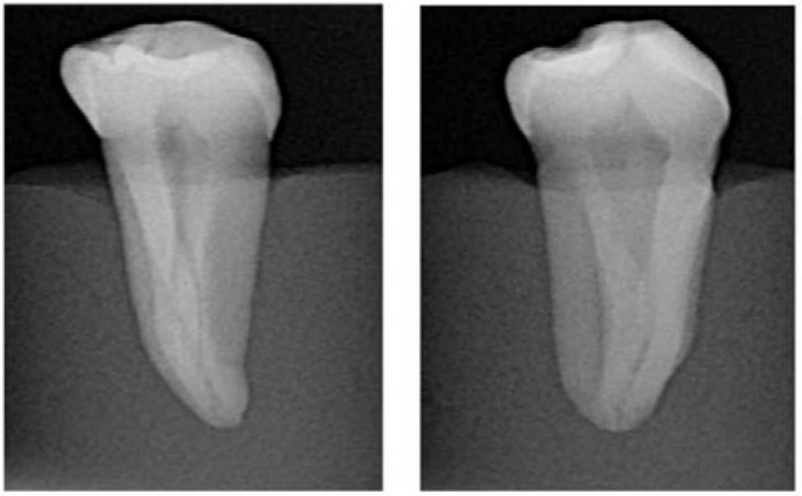

(b)
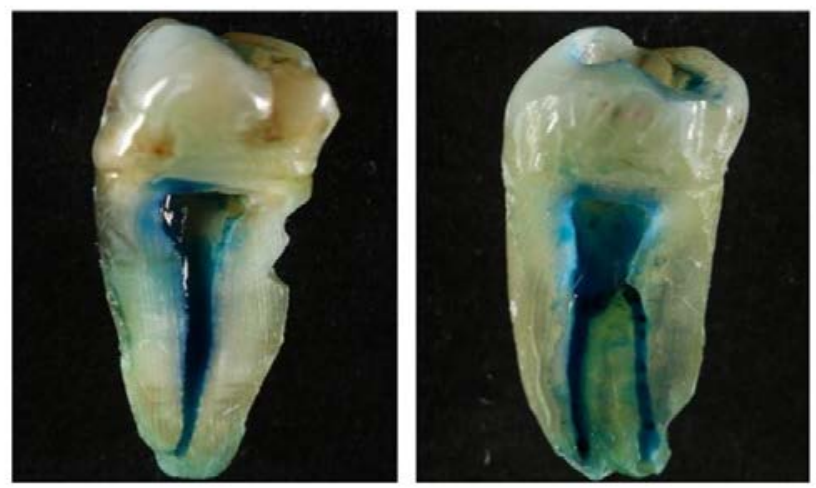

Figure (2): (a) Pre-operative digital periapical Images, (b) Samples displaying root canal anatomy highlighted by methylene blue dye after root being ground buccolingually by diamond bur mounted on high speed handpiece.

Conservative endodontic access cavity was made in each sample using rose head, safe-end and endo-z burs mounted on high speed hand-piece (Dentsply Sirona, New York, USA). Methylene blue dye (Alpha Chemika, Mumbai, India) was injected into canal system through prepared access cavities using injection syringes aided by apical vacuuming. Finally, root of each tooth was sectioned by selective grinding longitudinally buccolingually using long shank diamond bur mounted on high-speed hand piece until visualizing the canal system. (Figure-2)

Evaluation of periapical radiographs was done entirely by five calibrated experienced endodontists blindly and independently according to Vertucci's classification, and inter-examiner reliability tests were performed between evaluators. Evaluation of resected dyed samples was done entirely by the principal investigator according to Vertucci's classification. Data were collected and then statistically analyzed.

\section{Statistical analysis:}

The minimal sample size was calculated based on a study aimed to determine the prevalence of the second mesiobuccal canal (MB2) in 100 maxillary first molars using three methods (13). A sample size of 114 specimens is the enough required sample size, as statistically significant with $80 \%$ power ( $\beta=20 \%)$, and at significance level of $95 \%(\alpha=0.05)(26)$.

Kappa test for agreement was used to measure degree of agreement and reliability between the 5 evaluators who carried out periapical radiography images analysis. Descriptive comparisons and data analysis were carried out using IBM SPSS software package version 20.0. (Armonk, NY: IBM Corp). The Chi-square test was used for intergroup comparison and significance level was set at $(\mathrm{P} \leq 0.05)$. 


\section{RESULTS}

\section{A. Evaluators agreement in Periapical Radiography images analysis}

Periapical Radiography images of the 118 teeth were interpreted by 5 different evaluators independently and blindly. Inter-examiner reliability test was carried out between evaluators readings of Periapical Radiography images using kappa test. high level of agreement was recorded with $\mathrm{K}$ value ranges from (0.881 to 0.962 ).

B. Prevalence of root canal configurations detected by Teeth sectioning and Periapical Radiography for the 118 teeth according to Vertucci's classification

Teeth sectioning confirmed 90 teeth (76.3\%) having singlecanal system (type-I), confirmed 26 teeth (22\%) having Two-Canals system with 20 teeth (16.9\%) having type-V configuration and 6 teeth (5.1\%) having type-III configuration, and also confirmed 2 teeth (1.7\%) having Three-Canal system. (Table-1)

After high level of agreement was confirmed between the 5 evaluators in periapical radiography analysis. The 5 Periapical Radiography readings of the 5 evaluators for the 118 teeth were combined in one reading for the 118 teeth based on agreement between at least 3 evaluators.

Combined periapical radiography analysis showed 84 teeth (71.2\%) having single-canal system (type-I), 29 teeth (24.6\%) having Two-Canals system with 24 teeth (20.4\%) having type-V configuration, 2 teeth $(1.7 \%)$ having type-II configuration, 2 teeth having type-VII configuration, 1 tooth (.8\%) having type-VI configuration, and 5 teeth (4.2\%) having Three-Canal system. (Table-1)

Periapical Radiography readings agreed with sectioning readings in 94 teeth (79.7\%), and failed to correctly identify 24 teeth (20.3\%). There was a statistically significant difference between Periapical Radiography and Teeth sectioning readings as $(\mathrm{P}<0.05)$. (Table-2) (Table-3)

Table (1): Showing prevalence of root canal configurations detected by Teeth sectioning and Periapical Radiography for the 118 teeth according to Vertucci's classification.

\begin{tabular}{|c|c|c|c|c||}
\hline \multirow{2}{*}{$\begin{array}{c}\text { Vertucci's } \\
\text { Classification }\end{array}$} & \multicolumn{2}{|c|}{$\begin{array}{c}\text { Preapical } \\
\text { (n= 118) }\end{array}$} & \multicolumn{2}{c|}{$\begin{array}{c}\text { Sectioning } \\
\text { (n= 118) }\end{array}$} \\
\cline { 2 - 5 } & No. & $\%$ & No. & $\%$ \\
\hline I & 84 & 71.2 & 90 & 76.3 \\
\hline II & 2 & 1.7 & 0 & 0.0 \\
\hline III & 0 & 0.0 & 6 & 5.1 \\
\hline IV & 0 & 0.0 & 0 & 0.0 \\
\hline V & 24 & 20.4 & 20 & 16.9 \\
\hline VI & 1 & 0.8 & 0 & 0.0 \\
\hline VII & 2 & 1.7 & 0 & 0.0 \\
\hline VIII & 0 & 0.0 & 0 & 0.0 \\
\hline Other & 5 & 4.2 & 2 & 1.7 \\
\hline
\end{tabular}

Table (2): Showing Agreement between Periapical Radiography and Teeth sectioning readings for the 118 teeth according to Vertucci's classification.

\begin{tabular}{||c|c|c|c|c|c|c|c|c||}
\hline & \multicolumn{7}{|c||}{ Teeth sectioning } \\
\cline { 3 - 8 } $\begin{array}{c}\text { Vertucci's } \\
\text { Classifi } \\
\text { cation }\end{array}$ & $\mathbf{I}(\mathbf{n = 9 0 )}$ & $\begin{array}{c}\text { II } \\
(\mathbf{n}=\mathbf{0})\end{array}$ & $\begin{array}{c}\text { III } \\
(\mathbf{n}=\mathbf{6})\end{array}$ & $\begin{array}{c}\mathbf{V} \\
(\mathbf{n}=\mathbf{2 0})\end{array}$ & $\begin{array}{c}\text { VI } \\
(\mathbf{n}=\mathbf{0})\end{array}$ & $\begin{array}{c}\text { VII } \\
(\mathbf{n}=\mathbf{0})\end{array}$ & $\begin{array}{c}\text { Other } \\
(\mathbf{n}=\mathbf{2})\end{array}$ & $\begin{array}{c}\text { Total } \\
(\mathbf{n}=\mathbf{1 1 8})\end{array}$ \\
\hline Periapical & & & & & & & & \\
\hline I & $\mathbf{8 1}$ & 0 & 1 & 2 & 0 & 0 & 0 & 84 \\
II & 2 & $\mathbf{0}$ & 0 & 0 & 0 & 0 & 0 & 2 \\
III & 0 & 0 & $\mathbf{0}$ & 0 & 0 & 0 & 0 & 0 \\
V & 6 & 0 & 3 & $\mathbf{1 3}$ & 0 & 0 & 2 & 24 \\
VI & 0 & 0 & 0 & 1 & $\mathbf{0}$ & 0 & 0 & 1 \\
VI & 1 & 0 & 0 & 1 & 0 & $\mathbf{0}$ & 0 & 2 \\
I & & 0 & 2 & 3 & 0 & 0 & $\mathbf{0}$ & 5 \\
Ot & 0 & 0 & 2 & \\
her & 0 &
\end{tabular}

Highlighted bold numbers in the table represent matching agreed answers between grinding and periapical radiography. Other numbers represent nonmatching readings.

Table (3): showing statistical agreement between Periapical Radiography and Teeth sectioning readings for the 118 teeth.

\begin{tabular}{||l|c|c||}
\hline \multirow{2}{*}{ Agreement with Teeth sectioning } & \multicolumn{2}{c|}{$\begin{array}{c}\text { Periapical } \\
\text { (n= 118) }\end{array}$} \\
\cline { 2 - 3 } & No. & \% \\
\hline Agreed & 94 & 79.7 \\
\hline Not agreed & 24 & 20.3 \\
\hline P for comparison with Sectioning & \multicolumn{2}{|c|}{$<0.001 *$} \\
\hline
\end{tabular}

\section{DISCUSSION}

Vast majority of failed root canal treated teeth that require endodontic retreatment due to pain, apical periodontitis, or periapical radiolucencies fail mainly due to bacterial infection that often is caused by missed canals or leaky canals. Missing a canal during root canal treatment deteriorates treatment success tremendously, a left un-treated canal either infected or not increases failure rate either by harboring bacteria in sufficient numbers to maintain or cause disease, or if noninfected, by functioning as a potentially vulnerable site for reinfection $(21,22)$. In the present study, teeth sectioning and periapical radiography were selected to investigate root canal anatomy in mandibular premolars rather than teeth clearing in agreement with Assadian et al (2), and Lu et al (3) who used teeth sectioning to investigate root canal anatomy of mandibular premolars in different ethnic groups, and also in agreement with Khedmat et al (4) who reported using periapical radiography and teeth sectioning for canal anatomy investigations of mandibular premolars.

This was in contrary to Awawdeh and Al-Qudah (5), and Singh et al (6) who reported using teeth clearing for canal anatomy investigations. Drawbacks related to teeth clearing investigation methods were reported by Gupta et al (7) who reported damage to the tooth structure because of the decalcification by acid and post-decalcification clogging of the root canal.

In the current study, teeth were imbedded in acrylic resin blocks before pre-operative periapical imaging to relatively mimic bone and soft tissues radiographic noise in agreement with Michetti et al (8), and Assadian et al (2). This was different from what was done by Ordinola-Zapata et al (9), 
and Khademi et al (10) who reported using wax. In-accurate fitting of tooth roots in empty sockets of human or animal mandibles in the current study hindered the use of bone. Each specimen was scanned by periapical digital sensor from two clinically applicable horizontal angles $0^{\circ}$ and $20^{\circ}$ instead of direct proximal scanning to ensure standardized mimicking of clinical situation, and this was in agreement with Matherne et al (11), and Domark et al (12).

In the current study, teeth sectioning was done manually by selective limited grinding of root surface buccolingually till visualizing highlighted root canal anatomy instead of automated longitudinal straight-line sectioning that may damage studied canal due to presence of canals in the same tooth at different planes and also canals curvature. This was in agreement with Hiebert et al (13).

In the current study in an Egyptian population, Single-canal system (Type-I) was the most prevalent configuration in the 118 teeth with (76.3\%) followed by Type-V (16.9\%) and Type-III (5.1\%) and only (1.7\%) presented 3-Canal configuration. This was similar to what was reported by Awawdeh and Al-Qudah (5) in a Jordanian population and Pedemonte et al (16) in Belgian and Chilean populations. This was different from what was reported by Lizama et al (27) in a Mexican population who reported only (50\%) of investigated teeth having Single-canal system, and Singh et al (6) in an Indian population who reported significantly higher prevalence of two and three canal-systems.

Periapical images were analyzed independently by 5 experienced endodontists having the same academic qualifications after inter-evaluator reliability test that confirmed high level of agreement between all the 5 evaluators with $\mathrm{K}$ values ranged from (0.881 to 0.962$)$. The use of different evaluators in periapical images analysis instead of one evaluator was done to decrease bias and unreliability and this was in agreement with Khosravi et al (14) and Tolentino et al (15).

In the present study, Periapical Radiography readings agreed with sectioning readings in 94 teeth (79.7\%) only. There was a statistically significant difference between Periapical Radiography and Teeth sectioning readings as $(\mathrm{P}<$ 0.05). This was in accordance with Khedmat et al (4) who reported low accuracy of periapical radiography in ability to investigate root canal anatomy of mandibular premolars when compared to teeth sectioning, and also in agreement with Sousa et al (17) and Abuabara et al (18) who reported low accuracy of periapical radiography in ability to investigate root canal anatomy when compared to other investigation methods.

In the present study, periapical radiography failed to identify root canal configurations in 24 teeth (20.3\%) out of the 118 teeth. Miss-identifying root surface morphological features as root canal anatomy was the most common cause of failure of periapical radiography. Periapical radiography identified extra non-existing canals in 14 teeth, as it miss-identified 9 teeth to have Two-canal system while confirmed by sectioning to have One-canal system, and also missidentified 5 teeth to have Three-canal system while confirmed by sectioning to have Two-canal system. 13 teeth out of the 14 teeth miss-identified by periapical radiography having extra non-existing canal presented external radicular grooves on their root surfaces with varying degrees of invagination. Radicular grooves were miss-identified as canals by periapical radiography and this was in agreement with reports by Chen et al (19), and Sun et al (20).

\section{CONCLUSION}

Within the limitation of this study related to limited number of specimens and the availability of micro-computed tomography units, it was concluded that, prevalence of root canal anatomical variations in Egyptian mandibular premolars conforms with majority of previous studies carried out in different ethnic groups with no significant deviation, which displays that, presence of more than one canal in mandibular premolars is significant and more attention to this fact must be given. Periapical radiography is not reliable to investigate root canal anatomy of mandibular premolars with significant low accuracy; therefore, limitations of periapical radiography imaging must be fully recognized for accurate and reliable canal anatomy assessment. Sectioning investigation technique of root canal anatomy relatively overcame drawbacks related to clearing investigation techniques.

\section{CONFLICT OF INTREST}

The authors declare that they have no conflicts of interest

\section{REFERENCES}

1. Karabucak B, Bunes A, Chehoud C, Kohli MR, Setzer F. Prevalence of apical periodontitis in endodontically treated premolars and molars with untreated canal: a cone-beam computed tomography study. J Endod. 2016; 42:538-41.

2. Assadian H, Dabbaghi A, Gooran M. Accuracy of CBCT, digital radiography and cross-sectioning for the evaluation of mandibular incisor root canals. Iran Endod J. 2016; 11:106-10.

3. Lu TY, Yang SF, Pai SF. Complicated root canal morphology of mandibular first premolar in a Chinese population using the cross section method. J Endod. 2006; 32:932-6.

4. Khedmat S, Assadian H, Saravani AA. Root canal morphology of the mandibular first premolars in an Iranian population using cross-sections and radiography. J Endod. 2010; 36:214-7.

5. Awawdeh LA, Al-Qudah AA. Root form and canal morphology of mandibular premolars in a Jordanian population. Int Endod J. 2008; 41:240-8.

6. Singh S, Pawar M. Root canal morphology of South Asian Indian mandibular premolar teeth. J Endod. 2014; 40:1338-41.

7. Gupta B, Tiwari B, Raj V, Kashyap B, Chandra S, Dwivedi N. Transparent tooth model: A study of root canal morphology using different reagents. European J Gen Dent. 2014; 3:66.

8. Michetti J, Maret D, Mallet JP, Diemer F. Validation of cone beam computed tomography as a tool to explore root canal anatomy. J Endod. 2010; 36:1187-90.

9. Ordinola-Zapata R, Bramante CM, Versiani MA, Moldauer BI, Topham G, Gutmann JL et al. Comparative accuracy of the Clearing Technique, CBCT and Micro-CT methods in studying the mesial root canal configuration of mandibular first molars. Int Endod J. 2017; 50:90-6.

10. Khademi A, Mehdizadeh M, Sanei M, Sadeqnejad H, Khazaei S. Comparative evaluation of root canal 
morphology of mandibular premolars using clearing and cone beam computed tomography. Dent Res J. 2017; 14:321.

11. Matherne RP, Angelopoulos C, Kulild JC, Tira D. Use of cone-beam computed tomography to identify root canal systems in vitro. J Endod. 2008; 34:87-9.

12. Domark JD, Hatton JF, Benison RP, Hildebolt CF. An ex vivo comparison of digital radiography and cone-beam and micro computed tomography in the detection of the number of canals in the mesiobuccal roots of maxillary molars. J Endod. 2013; 39:901-5.

13. Hiebert BM, Abramovitch K, Rice D, Torabinejad M. Prevalence of second mesiobuccal canals in maxillary first molars detected using cone-beam computed tomography, direct occlusal access, and coronal plane grinding. J Endod. 2017; 43:1711-5.

14. Khosravi Z, Moshfeghi M, Samiei N. Validity and reliability of cone beam computed tomography for assessing mesial root canal type in mandibular first molars. Int J Res 2017; 4:2625-8.

15. Tolentino E, Amoroso-Silva PA, Alcalde MP, Honório HM, Iwaki LC, Rubira-Bullen IR et al. Accuracy of High-resolution Small-volume Cone-beam Computed Tomography in Detecting Complex Anatomy of the Apical Isthmi: Ex Vivo Analysis. J Endod. 2018; 44:1862-6.

16. Pedemonte E, Cabrera C, Torres A, Jacobs R, Harnisch A, Ramírez $\mathrm{V}$ et al. Root and canal morphology of mandibular premolars using cone-beam computed tomography in a Chilean and Belgian subpopulation: a cross-sectional study. Oral Radiol. 2018; 34:143-50.

17. Sousa TO, Haiter-Neto F, Nascimento EH, Peroni LV, Freitas DQ, Hassan B. Diagnostic accuracy of periapical radiography and cone-beam computed tomography in identifying root canal configuration of human premolars. J Endod. 2017; 43:1176-9.

18. Abuabara A, Baratto-Filho F, Aguiar anele J, Leonardi DP, Sousa-Neto MD. Efficacy of clinical and radiological methods to identify second mesiobuccal canals in maxillary first molars. Acta Odontol Scand. 2013; 71:205-9.
19. Chen J, Li X, Su Y, Zhang D, Wen X, Nie X et al. A micro-computed tomography study of the relationship between radicular grooves and root canal morphology in mandibular first premolars. Clin Oral Invest. 2015; 19:329-34.

20. Sun Y, Lu TY, Chen YC, Yang SF. The best radiographic method for determining root canal morphology in mandibular first premolars: A study of Chinese descendants in Taiwan. J Dent Scien. 2016; 11:175-81.

21. Yamaguchi M, Noiri Y, Itoh Y, Komichi S, Yagi K, Uemura $\mathrm{R}$ et al. Factors that cause endodontic failures in general practices in Japan. BMC oral health. 2018; 18:70.

22. Costa FF, Pacheco-Yanes J, Siqueira Jr JF, Oliveira AC, Gazzaneo I, Amorim CA et al. Association between missed canals and apical periodontitis. Int Endod J. 2019; 52:400-6.

23. Hess W, Zurcher E. The anatomy of root canals of the teeth of the permanent and deciduous dentitions. JAMA. 1925; 85:2052.

24. Vertucci F, Seelig A, Gillis R. Root canal morphology of the human maxillary second premolar. Oral Surgery, Oral Medicine, Oral Pathol. 1974; 38:456-64.

25. ert S, Bayirli GS. Evaluation of the root canal configurations of the mandibular and maxillary permanent teeth by gender in the Turkish population. J Endod. 2004; 30:391-8.

26. Daniel WW. Biostatistics: A Foundation for Analysis in the Health Sciences. 6th Ed, New York: John Wiley \& Sons Inc; 1995.

27. Lizama EM, Tiesler V, Chi-Keb JR, Ramírez-Salomón M, Hernández-Mejía A, Cucina A. Root Canal Morphology of the Mandibular First Premolars in a Yucatecan Population Using Cone Beam Computed Tomography: An in vitro Study. Int J Morphol. 2018; 36:1216-21. 